has been met would, on the above supposition, recenve a simple explanation in the varying mean densities of the balloon and its contained gas on different occasions, since the balloon will come to rest when its mean density is equal to that of the air in which it floats.

In this connection it may not be out of place to recall that an increased velocity of the balloon does not indicate an ascensional current, nor does a decreased velocity indicate a downpour of air. In the latter case, what has more probably happened is that the balloon has crossed a surface of discontinuity in density, and is less buoyant. J. I. CRAIG.

Survey Department, Giza, Egypt, December 5, 1908.

IT does not appear to me that the explanation suggested by $\mathrm{Mr}$. Craig is tenable. 'I will first state that the instruments used in England are calibrated over the whole range of conditions to which they may be exposed by placing them in a glass vessel so that they are completely covered by liquid which has been cooled to the desired temperature by solid $\mathrm{CO}_{2}$, and then exhausting the air by a pump. Thus the instrument is exposed at the same time to the conditions of pressure and temperature which it will meet with in use. This is done both before and after each ascent, unless, as sometimes happens, such damage is done by the finder as to render the second calibration impossible. On the Continent, at one station at least, and perhaps at most, the pressure is reduced slowly for the express purpose of meeting the point raised by Mr. Craig. In England, and for the same reason, air is generally left in the aneroid box. Very thin metal is used; the box is dried, the faces are squeezed together so that they nearly touch, and the box is then sealed up. The result is that the pressure scale depends on the elasticity of the enclosed air chiefly, and only slightly on the elasticity of the metal. Of course, there is a large correction for temperature which involves extra trouble in the calibration, but, on the whole, I believe this system to be the more accurate.

The lag of an aneroid box no doubt produces the results described by $\mathrm{Mr}$. Craig, but the error so produced, when expressed as a percentage of the whole deflection of the box, is, I think, small. We have many records in which the isothermal part of the trace covers more than $100 \mathrm{~mm}$. of pressure, and an error of this magnitude could not possibly be produced by the elastic fatigue of the box. Further, in general the balloons burst while they are rising; they start with an ascensional velocity of more than 600 feet per minute, and we have good ground for thinking that the pace is accelerated towards the top. They fall in about half the time they take to rise, and hence, unless there be an isothermal layer, the instrument cannot remain in air at the same temperature for sufficient time for the slow expansion of the box to take place. If further evidence is required it may be given in the fact that the up and down traces show, with hardly an exception, practically identical temperatures, especially in the isothermal region, where, if a lag came into play, they ought to be most divergent.

With regard to ascending and descending currents, we know from our experience with kites that such exist. The pressure of the air must be continuous, but discontinuity in the density may arise from an inversion, the temperature suddenly rising with the height. Five degrees centigrade is a not uncommon amount, but this means a change of density of less than 2 per cent. The free lift of a balloon in these ascents is about equal to the whole weight lifted, and hence a sudden change of $5^{\circ} \mathrm{C}$. may mean a change of 4 per cent. in the free lift. To meet this the square of the velocity must change by 4 per cent. and the velocity by 2 per cent. This is of quite a different order to the observed variations in the vertical velocity, which in the lower strata may reach 50 or more per cent. It would be of interest to know the rate at which the gas inside approximates to the outside temperature, and the amount of difference which may arise from solar insolation.

No doubt the point raised by Mr. Craig is an important one, and may lead to serious errors in the height unless especial care is taken to guard against it, but it cannot account for the observed phenomena. In England, at least, we have never claimed great accuracy in the recorded heights, and I do not believe such accuracy to be possible, but our traces show the commencement of the isothermal part at 10 to 12 kilometres, and the balloons often reach is kilometres. That elastic fatigue can account for the space between II and 18 kilometres is out of the question.

W. H. Dines.

\section{Curious Effect of Surface Ablation of a Glacier.}

DURING a traverse of the Gorner Glacicr last summer, a peculiar feature in connection with the surface ablation came to my notice which I have never seen described or even referred to. I therefore venture to give a short description of this interesting phenomenon. The surface of the glacier is studded with the usual pools of clear water, due to clusters of small stones which become heated and sink some distance in the ice, the north and south retaining walls of the pool sloping in a northerly direction.

On the southern or sunny side of most of the pools there was a spine-like projection of ice standing vertically from the general surface, and tapering upwards to a jagged knife-edge with an east and west alignment. Upon the northern rather flat (or slightly concave?) sides of these spines there were sometimes vertical ridges, and at irregular intervals the remains of thin, horizontal shelves of ice, which represented former levels of the water in the

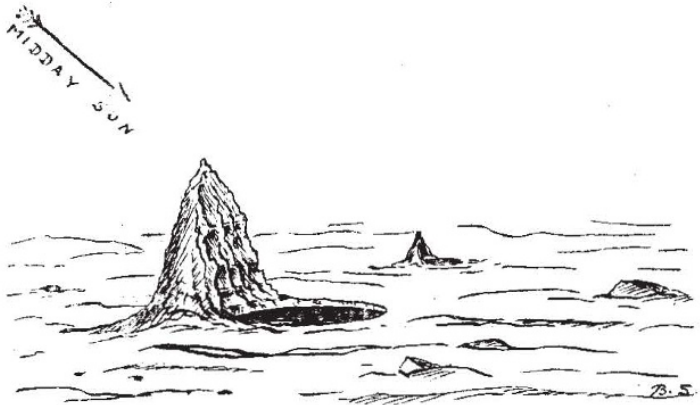

Spine-like projections of ice upon the sunny side of pcols (formed by clusters of small stones) on the Gorner Glacier, August, 1908. Height about $x 8$ inches.

pools. The sketch roughly shows this disposition. At the time there was no opportunity of making accurate measurements; many of the spines, however, were at least 18 inches high, and there appeared to be a proportional relation between the height, width, and breadth of the spine and the width and depth of the pool. Apparently each projection is the relic of what was the southern wall of the pool when the general surface of the glacier was at a higher level (as shown by the horizontal shelves of ice), and which by some means, perhaps partly because that wall is in shade, has been maintained at a low temperature, and thus enabled to resist the general surface ablation.

Blackheath.

Bernard Smith.

\section{Moral Superiority?}

Is this worthy of record as exceptional? I fed the birds with soft lumps of bread (not crumbs) this morning; there was a strong frost and 6 inches of snow. The first instant arrivals were two redbreasts and a blue tit. All three flew to the same lump of bread; but the little tit turned with fury on his two (ordinarily) combatant opponents, drove them away, and-while I watched-took his fill of the bread he had won until the usual crowd of sparrows appeared, when he decamped with what was left of his meal, and then the redbreasts-as always-ruled the roost. F. C. Constable.

Wick Court, near Bristol, December 30, Igo8. NO. 2045, VOL. 79] 